\title{
A Faculdade Interamericana de Educação na expansão da pós-graduação no Brasil ${ }^{*}$
}

\author{
Clovis Renan Jacques Guterres
}

Universidade Federal de Santa Maria, Centro de Educação

Oswaldo Alonso Rays

Centro Universitário Franciscano de Santa Maria

\section{Introdução}

Neste artigo analisamos a criação e a implementação da Faculdade Interamericana de Educação (FIE), um dos primeiros mestrados em educação no interior do Brasil, no período de 1970 a 1977, dentro do Projeto Multinacional de Aperfeiçoamento de Pessoal Especializado em Educação, desenvolvido a partir de um convênio entre o governo brasileiro e a Organização dos Estados Americanos (OEA). O objetivo desse projeto foi o aperfeiçoamento de pessoal docente para o ensino médio na América Latina e, nesse sentido, volta-se para a formação de técnicos da educação e administradores escolares em nível de pós-graduação. Instalada na cidade de Santa Maria, no estado do Rio Grande do Sul, a FIE deu origem ao atual Programa de Pós-Graduação em Educação da Universidade Federal de Santa Maria (UFSM).

A análise dessa experiência de pós-graduação é realizada tendo como parâmetros as relações de interdependência com o contexto histórico, político, econômico, social e educacional mais amplo que lhe serve de pano de fundo e do qual, supomos, emanaram as diretrizes que lhe deram existência e consis-

* Artigo elaborado com base na pesquisa que deu origem à tese de doutorado de Clóvis R. J. Guterres (2001). tência. Assim sendo, a FIE não pode ser compreendida na sua singularidade se não for investigada a totalidade maior da qual ela é expressão, seja em nível internacional (OEA), em nível nacional (Ministério da Educação - MEC), ou em nível local (UFSM).

Nessa linha de investigação, a experiência foi analisada com base em suas relações com os elementos conjunturais e estruturais que lhe deram suporte. Embora o projeto multinacional tenha se desenvolvido de 1970 a 1977, a investigação retrocedeu a 1967, ano do Encontro dos Chefes de Estado da América, em Punta del Este, do qual esse projeto se originou, tendo sido aprovado na $5^{\circ}$ Reunião do Conselho Interamericano Cultural da OEA, realizada em fevereiro de 1968, na cidade de Maracay, na Venezuela. Em contrapartida, a política de apoio à pós-graduação pela OEA, nesse período, só pode ser compreendida no contexto da Guerra Fria, iniciada em 1947, após o fim da $2^{\circ}$ Grande Guerra em 1945, quando o mundo se dividiu em dois grandes blocos ideológicos: um, capitalista, liderado pelos Estados Unidos da América (EUA), e outro, comunista, liderado pela União Soviética.

Nesse sentido, identificamos os seguintes condicionantes na criação e estruturação da FIE: o deslocamento da Guerra Fria do palco europeu para a periferia, após a década de 1950, principalmente para a Ásia e a América Latina; a criação da OEA em 1948, 
decorrente da reformulação da União Pan-americana, refletindo as diretrizes emanadas dos confrontos da Guerra Fria; a política de pós-graduação no Brasil, que, após o golpe militar de 1964, abandonava a influência predominantemente européia e tomava o modelo norte-americano de pós-graduação como modelo oficial; e a política da UFSM, que, na época, defendia, por meio do Projeto Nova Universidade (PNU), a interiorização da universidade e sua vinculação ao desenvolvimento regional.

O estudo da FIE apoiou-se basicamente na análise da documentação e do arquivo existente no setor de documentação da Biblioteca Setorial do Centro de Educação da UFSM, complementado com depoimentos de ex-gestores, ex-funcionários, ex-professores e ex-alunos da FIE. Os depoimentos tiveram dupla função: acrescentar informações não contidas no arquivo, ou esclarecê-las em caso de dúvida, e avaliar as atividades da FIE no sentido de expressar satisfação ou insatisfação com o mestrado, bem como ajudar a reconstituir o clima acadêmico vivido e a integração pretendida.

A maior parte dos documentos relacionados à origem do convênio entre o MEC e a OEA consta do primeiro processo de credenciamento, de dezembro de 1969, encaminhado ao reitor da UFSM, que por sua vez o encaminhou ao Conselho Federal de Educação (CFE) em janeiro de 1970. A documentação essencial referente ao desenvolvimento do projeto multinacional é constituída pelos planos operacionais, planos de curso, atas de seleção, atas de defesa de dissertação, relatórios de atividades, relatórios de alunos, balancetes financeiros, alterações administrativas e normativas.

O projeto multinacional envolveu 18 países da América Latina, com a participação de 228 alunos, 120 brasileiros e 108 estrangeiros. Desse total, 138 obtiveram o título de mestre, e os demais, de especialista.

A intenção de investigar as origens e o desenvolvimento do Programa de Pós-Graduação em Educação decorreu de uma série de controvérsias e estigmas que se originaram com base no fato de os responsáveis pela execução do convênio decidirem por não submetê-lo à avaliação da Coordenação de Aperfeiçoamento de Pessoal de Nível Superior (CAPES), alegando que se tratava de um projeto multinacional. O não-credenciamento, à época, trouxe sérias conseqüências para o desenvolvimento posterior do mestrado, mesmo após o seu credenciamento em 1980, como mestrado em educação da UFSM. Outro aspecto controverso desse projeto multinacional foi a sua incompatibilidade com a legislação de pósgraduação vigente no Brasil desde 1965 e consolidada em 1969, cujas diferenças assentam, principalmente, no tempo dedicado à realização dos créditos e da dissertação. ${ }^{1}$ Além do mais, o mestrado em educação oferecido pela FIE, como veremos, guardou ainda a qualidade das atividades acadêmicas decorrentes dos parâmetros epistemológicos adotados, qualidade esta questionada por muitos educadores ligados à pós-graduação brasileira.

\section{O contexto histórico da constituição da FIE}

Na Conferência de Bogotá, realizada em 1948, o pós-guerra definiu novos rumos para as organizações internacionais, levando à criação da OEA. ${ }^{2}$ As conferências e reuniões de consulta que se sucedem após a sua fundação são basicamente marcadas pelo combate à expansão comunista. Na $4^{\mathrm{a}}$ Reunião de Consulta, em 1951, os ministros de estado presentes de-

${ }^{1} \mathrm{O}$ curso tinha a duração total de 10 meses, perfazendo um total de 1.500 horas, distribuídas em dois turnos diários de atividades, com a supervisão de corpo docente permanente.

${ }^{2}$ Nessa reunião, como analisa Bicudo (2002), foram aprovados “dois importantíssimos instrumentos jurídicos em matéria de direitos humanos: a Carta da Organização dos Estados Americanos e a Declaração Americana dos Direitos e Deveres do Homem, aprovadas em 2 de maio de 1948, sete meses antes da Declaração Universal dos Direitos Humanos, proclamando os direitos fundamentais da pessoa, sem distinção de raça, nacionalidade, credo religioso, sexo e estabelecendo como um dos direitos fundamentais dos Estados o de respeitar os direitos da pessoa humana”. 
cidiram "tomar medidas ante la amenaza a la paz del hemisfério creada por la política expansionista del comunismo internacional” (OEA, 1972a, p. 31). Na $10^{a}$ Conferência Interamericana, em 1954, após o fim da Guerra da Coréia, "se dio nueva orientación a la política y programas de la OEA formulados para los cinco años siguientes y se recalcó el desarrollo económico, social y cultural” (idem, p. 29). Mas foi na $8^{\text {a }}$ Reunião de Consulta, realizada em Punta del Este, Uruguai, em janeiro de 1962, que se deliberou sobre a suspensão de Cuba da OEA. Pode-se afirmar que, a partir daí, a América Latina foi atingida de forma intensa pela Guerra Fria e pelas políticas de integração da OEA. A preocupação com a pobreza na América Latina como fonte de exploração política pelos grupos de esquerda, principalmente após a Revolução Cubana, levou os norte-americanos a uma mudança de estratégia em relação à região, com a proposição da Aliança para o Progresso pelo presidente norte-americano John Kennedy, em 1961.

Em 1967, no Encontro dos Chefes de Estado da América, reunidos em Punta del Este, estabeleceu-se o propósito de "fortalecer la Aliança para el Progreso y llegar a un acuerdo sobre nuevos métodos técnicos de cooperación multilateral para acelerar la integración de la América Latina” (idem, p. 32). Coube ao Conselho Interamericano Cultural a implementação das políticas de desenvolvimento educacional da OEA, e, em reunião realizada em Maracay, na Venezuela, em 1968, as propostas e os projetos sobre educação, ciência, tecnologia e cultura elaborados pela Comissão de Educação $a d-h o c$ e o Grupo de Peritos em Ciência e Tecnologia foram apreciados pelas comissões de trabalho constituídas para esse evento.

Dos estudos empreendidos resultaram 33 resoluções, sendo a primeira e a mais importante delas denominada Resolução de Maracay, pela qual foram aprovados o Regime Orgânico do Conselho Interamericano Cultural e seus programas regionais. Para o Programa Regional de Educação foram estabelecidos como objetivos: elevar a qualidade da educação, promover a pesquisa e a incorporação de métodos modernos na educação e nos setores afins, impulsionar a cooperação interamericana em matéria educacional e, principalmente,

[...] promover a integração latino-americana por meio da educação, com o propósito de elevar o nível econômico e social da região e como passo importante no sentido da criação de uma comunidade latino-americana no setor da educação, respeitada a personalidade educacional e cultural dos povos. (A Crônica da OEA, 1968, p. 24)

No Informe Final de la Primera Reunión (OEA, 1969a) foi apresentado o Proyecto Multinacional de Perfeccionamiento de Personal Especializado en Educación, com objetivos, indicação das instituições responsáveis, atividades e metas a serem desenvolvidas e orçamento proposto. Entre as sete instituições educacionais indicadas para sediar o projeto, duas eram brasileiras: o Centro Regional de Pesquisas Educacionais Dr. Queirós Filho, em São Paulo, e a UFSM, que, entre as atividades e metas propostas, se insere no item 3, letra c:

Universidade Federal de Santa Maria, em Santa Maria, Rio Grande do Sul, Brasil. Se ofrecerán cursos de postgrado de un año de duración para la formación de especialistas en curriculum. El primer semestre se destinará para la programación de los cursos. (idem, p. 35)

É necessário fazer outra retomada histórica para entender o porquê de uma universidade do interior, fundada em 1960, ter sido escolhida para sediar o projeto multinacional. Esse entendimento passa pela discussão do papel representado pelo PNU, desenvolvido a partir do texto "Universidade e progresso da humanidade”, de autoria do fundador e primeiro reitor da UFSM, Mariano Rocha Filho (1962b). Nesse texto, o reitor afirma que a realidade brasileira é marcada por contrastes de civilização e atraso, opulência e miséria, típicas de um país que se concentrou no litoral e esqueceu o interior. Segundo ele, essa condição de civilização litorânea fez com que as universidades fossem concentradas especialmente nas capitais, reproduzindo internamente uma espécie de 
colonialismo educacional em relação às populações interioranas.

A partir dessa análise, o PNU propõe uma mudança profunda nos objetivos e nas estruturas da universidade vigente, como forma de adaptá-la ao processo de desenvolvimento e transformá-la em alavanca para o progresso. Apesar das amarras da legislação em vigor desde o Estatuto das Universidades Brasileiras, de 1931, propõe um plano de estruturação de uma universidade moderna fundada em três tipos de unidades: faculdade, instituto e departamento. A introdução do instituto rompia com a velha universidade centrada no caráter profissionalizante das faculdades, voltando-se para a priorização da pesquisa, à semelhança das universidades modernas, inspiradas no modelo da Universidade de Berlim. Ressalvadas as posições políticas conservadoras que permeiam o texto, as propostas apresentadas nesse projeto eram, sem dúvida, inovadoras.

A mudança estrutural proposta apontava, também, para outras necessidades: relação entre a universidade, a sociedade e a cultura; relação entre a universidade e o operariado; participação dos alunos nos colegiados da universidade; ensino com alunos em dedicação exclusiva; ensino centrado na prática; bolsas de estudo rotativas, especialmente aos alunos pobres; adoção de um plano de carreira como forma de superar os problemas apresentados pela cátedra; criação do regime de tempo integral ou de dedicação exclusiva; e valorização da pesquisa. O PNU teve seus estatutos aprovados em junho de 1962 pelo Conselho Universitário e vigorou até 1969, quando a Reforma Universitária instituída pela lei $n^{0}$ 5.540/68 exigiu a reestruturação da UFSM.

A posição política ocupada por Rocha Filho nos ajuda a entender a escolha da UFSM para sediar a FIE. Na Reunião do Conselho Interamericano Cultural em Maracay, Rocha Filho participou como assessor do ministro da Educação e Cultura, Tarso Dutra. Ainda no Rio de Janeiro, antes de embarcar para Caracas, já famoso pela construção da primeira universidade pública no interior do país, concedeu entrevista ao Correio da Manhã, do Rio de Janeiro, publicada com o título "Reitor propõe Universidade das Américas”, em 16 de fevereiro de 1968, dois dias após o início do evento. O jornal destacava: “O reitor José Mariano da Rocha Filho, da Universidade Federal de Sta. Maria (RS), apresentará à conferência dos ministros de Educação dos países americanos, na cidade de Maracay, Venezuela, o projeto de sua autoria criando a Universidade das Américas”. Em sua declaração, Rocha Filho é mais modesto do que a chamada do periódico: “O projeto não é oficial, mas uma simples sugestão que espera, entretanto, merecer boa acolhida do plenário da V Reunião do Conselho Interamericano Cultural da OEA”.

Gestada em um encontro de reitores de universidades realizado no Chile e proposta, posteriormente, durante uma visita à sede da OEA, a idéia consistia em transformar a UFSM na Universidade das Américas, devido à sua localização e à modernidade de suas estruturas. Essa idéia havia sido esboçada anteriormente em um texto publicado no jornal A Razão, em 9 de outubro de 1966, com o título "A Universidade das Américas no Brasil”. Entretanto, no final da entrevista de 1968, o reitor deixa de se referir a Universidade das Américas para declarar: “o ministro Tarso Dutra vai apresentar no conclave o projeto prioritário para a criação, em Sta. Maria, de uma Faculdade Interamericana de Educação” (idem).

Embora o professor Rocha Filho insistisse que a idéia da Universidade das Américas teria sido bem aceita na OEA, o que de fato germinou foi a FIE. ${ }^{3}$

${ }^{3}$ Essa denominação deve-se à resistência, nos EUA, às Faculdades de Filosofia, Ciências e Letras, e à recomendação de vinculá-la a um setor de educação. Para solucionar o problema, desenvolveu-se um projeto de criação de uma Faculdade de Educação que, subordinada ao projeto multinacional, passa a denominar-se Faculdade Interamericana de Educação. Entretanto, com o plano de reestruturação da UFSM e a aprovação, em 1970, de seu novo estatuto, eliminam-se de sua estrutura organizacional as faculdades e institutos. A FIE sobreviveu à reestruturação na qualidade de projeto, mas não de unidade; tanto é que, no organograma da UFSM, elaborado em conformidade com o novo estatuto, aparece apenas como curso de pós-graduação em educação. 


\section{A FIE e o início da pós-graduação em educação na UFSM}

Em 1968 foi definido o funcionamento da FIE, por meio de um convênio entre a OEA e o governo brasileiro. Conforme os documentos oficiais, os responsáveis pela execução do projeto seriam o MEC do Brasil, por meio da Coordenação de Aperfeiçoamento de Pessoal de Nível Superior (CAPES), e a UFSM.

$\mathrm{O}$ argumento base para a criação da FIE referese à falta de pesquisa e de pessoal qualificado, como se pode perceber na seguinte passagem retirada de seu projeto de estruturação:

É notória, no Brasil e na América Latina, de um modo geral, a falta de pesquisa em educação e da formação de educadores de alto nível (pós-graduação); é da mais alta importância que se instale uma entidade que supra não só essas deficiências - pura e simplesmente -, mas que execute, simultaneamente, verdadeira integração educacional Pan-Americana, com homogeneização paulatina dos processos educacionais em todo o Continente Americano. (UFSM, 1968, p. 1)

Nesse sentido, a FIE foi organizada a partir de quatro grandes objetivos:

A. Formar técnicos de educação e administradores escolares em nível de pós-graduação, fornecendolhes possibilidades teóricas e práticas de estudo concentrado em ciências e técnicas pedagógicas.

B. Estimular pesquisas educacionais e treinar pesquisadores, dotando os países latino-americanos de recursos humanos adequados.

C. Fomentar experiências nos diversos níveis da educação, e difundir, nesse campo, uma mentalidade experimental.

D. Promover o intercâmbio educacional entre os diversos sistemas dos países das Américas. (OEA, 1968, p. 32)

A estrutura inicial proposta para a FIE foi: uma direção, uma secretaria e três departamentos. No
Departamento de Cursos e Programas já se previa o caráter de mestrado do curso a ser oferecido, pois se assinalava: “o Departamento poderá prever, ainda, em fase posterior à da instalação da Faculdade, cursos especiais, sendo, no entretanto, a freqüência e aprovação nos cursos acima o requisito mínimo para o grau de Mestre” (UFSM, 1968, p. 5).

A instalação do mestrado, prevista para março de 1969, não foi efetivada em virtude de atraso na assinatura do convênio entre o Brasil e a OEA, assim como atrasos na organização do planejamento do curso e no recebimento dos recursos. O mestrado foi instalado, então, em janeiro de 1970. Nesse intervalo, foram realizadas duas reuniões preparatórias com os representantes da OEA, em fevereiro e novembro de 1969. A segunda reunião preparatória (OEA, 1969b) introduziu profundas modificações no projeto inicial, direcionando-o para um enfoque teórico-prático do currículo para o ensino médio, abrangendo as disciplinas de teoria e prática de currículo, teoria e prática de pesquisa em educação, e elementos de planejamento de educação. Foi alterada, também, a duração do curso e a distribuição das vagas entre brasileiros e estrangeiros: a duração, prevista inicialmente para 12 meses, foi reduzida para 10 meses; e das 30 vagas previstas no projeto inicial, sendo 21 para estrangeiros e 9 para brasileiros, passou-se para 15 para estrangeiros e 15 para brasileiros. Outra alteração diz respeito à nomenclatura: em lugar de Formação de Técnicos e Administradores Escolares, passou-se para Formação de Especialistas em Currículo para o Ensino Médio. Foram introduzidas, também, duas opções de titulação: mestre (créditos e trabalho de conclusão com defesa pública) e especialista (somente os créditos).

Dez dias após a instalação do curso de mestrado, foi proferida a aula inaugural pelo professor doutor Francisco Céspedes, diretor do Departamento de Assuntos Educativos (DAE) da OEA, com a presença do então ministro da Educação, Tarso Dutra. ${ }^{4}$

${ }^{4}$ Na ocasião, o Conselho Universitário da UFSM conferiu a Medalha de Mérito Universitário ao representante da OEA. 
A administração do curso de mestrado era dividida entre a direção e a coordenação. A primeira tinha um caráter de representação e gestão ampliada, enquanto a segunda tinha o papel de gerenciamento do curso, com a elaboração dos planos operacionais ${ }^{5} \mathrm{e}$ prestação de contas das aplicações orçamentárias, assim como a recepção e instalação dos bolsistas. O conselho de professores, além de assessorar a direção e a coordenação, era responsável pelo plano de curso, isto é, pelo desenvolvimento das atividades didático-pedagógicas.

A relação com o Departamento de Assuntos Educativos da OEA se efetivava por meio de farta correspondência, repasse de verbas para pagamento de bolsistas e compra de equipamentos e livros. Uma vez por ano, os diretores dos projetos reuniam-se para avaliar o desenvolvimento dos mesmos. Além disso, era comum a OEA enviar especialistas para avaliar, in loco, o funcionamento dos projetos.

A configuração organizacional e didático-pedagógica foi, no final de 1969, registrada no documento "Sugestiones para el Desarrollo de un Programa Particular de Currículo para el Nível Medio”6 e consolidada no seu programa geral, em termos de princípios, estrutura curricular e metodologia. A idéia matriz, contida na primeira parte do documento, era que o curso de mestrado, em razão da sua finalidade e de seus pressupostos, fosse desenvolvido a partir de um enfoque teórico-prático; ao contrário, portanto, da

${ }^{5}$ Durante o desenvolvimento do projeto multinacional foram elaborados oito planos operacionais. Com pequenas variações, esses planos obedeciam a uma seqüência lógica: objetivos, metas, estratégias, esquema operacional de execução de atividades e previsão orçamentária.

${ }^{6}$ Sem indicação de autoria, mas claramente vinculado às orientações da OEA, esse documento serviu de base para as reformulações que foram implementadas no projeto multinacional a partir da segunda reunião entre os coordenadores nacionais e representantes da OEA, realizado em novembro de 1968, para a adequação final da estrutura do curso de pós-graduação a ser oferecido pela FIE (OEA, 1969b). concepção tradicional, centrada nos estudos sistemáticos de textos clássicos e modernos referentes à matéria.

Essa proposta impôs uma mudança nas práticas e rotinas pedagógicas dos professores. A ênfase na relação teoria-prática e na integração das disciplinas levou-os, segundo depoimentos, a desenvolver a prática interdisciplinar e coletiva, não só planejando a forma de integração das disciplinas, mas ministrando-as conjuntamente a uma turma de alunos. A nova metodologia estabeleceu alguns procedimentos comuns, conforme o programa geral, que resumimos:

Instrução para os grandes grupos (IGG) - dirigido por um ou mais professores e algumas vezes devendo ser assistida por todos, quando assim se o requeresse, para assegurar uma maior unidade e integração do trabalho;

Trabalho em pequenos grupos (TPG) - orientado por todos os professores, mas, principalmente, pelos professores de Pesquisa, Planejamento e Estatística, que se encarregariam de orientar o trabalho em grupo e de guiar os alunos no que diz respeito ao planejamento e pesquisa de seus trabalhos. Estes trabalhos eram essencialmente de laboratório, partindo basicamente de situações-problema que após ampla e aprofundada discussão deveria chegar a um consenso, terminando obrigatoriamente com um informe escrito.

Estudo Individual (EI) - a ênfase no coletivo não eliminava o individual, preservando-o com o propósito de aprofundar conhecimentos. Parte do tempo destinado ao trabalho individual deveria ser ocupado na elaboração da ficha/relatório da semana.

Orientação de $\mathrm{Tese}^{7}$ - inicialmente era realizada em conjunto pelos professores; ao aluno era reservado um horário especial, no segundo semestre, para desenvolvê-la. (UFSM, 1970, p. 44-49)

A distribuição das atividades na semana, no ano de 1970, conforme o Quadro 1, expressa a relação com a metodologia adotada:

\footnotetext{
${ }^{7} \mathrm{O}$ programa geral não fazia a distinção entre tese e dissertação.
} 
Quadro 1 - Atividades da Faculdade Interamericana de Educação

\begin{tabular}{|c|c|c|c|c|c|c|}
\hline Hora & $2^{a}$ feira & $3^{a}$ feira & $4^{a}$ feira & $5^{a}$ feira & $6^{a}$ feira & Sábado \\
\hline $\begin{array}{l}08 \mathrm{~h} 30 \\
10 \mathrm{~h} 30\end{array}$ & $\begin{array}{l}\text { Currículo } \\
\text { IGG } \\
\text { Laboratório } \\
\text { TPG }\end{array}$ & $\begin{array}{l}\text { Currículo } \\
\text { IGG } \\
\text { Laboratório } \\
\text { TPG }\end{array}$ & $\begin{array}{l}\text { Currículo } \\
\text { IGG } \\
\text { Laboratório } \\
\text { TPG }\end{array}$ & $\begin{array}{l}\text { Currículo } \\
\text { IGG } \\
\text { Laboratório } \\
\text { TPG }\end{array}$ & $\begin{array}{l}\text { Currículo } \\
\text { IGG } \\
\text { Laboratório } \\
\text { TPG }\end{array}$ & $\begin{array}{l}\text { Currículo } \\
\text { IGG } \\
\text { Laboratório } \\
\text { TPG }\end{array}$ \\
\hline $\begin{array}{l}10 \mathrm{~h} 45 \\
12 \mathrm{~h} 00\end{array}$ & $\begin{array}{l}\text { Pesquisa } \\
\text { IGG }\end{array}$ & $\begin{array}{l}\text { Planejamento } \\
\text { IGG }\end{array}$ & $\begin{array}{l}\text { Estatística } \\
\text { IGG }\end{array}$ & $\begin{array}{l}\text { Currículo } \\
\text { IGG }\end{array}$ & $\begin{array}{l}\text { Planejamento } \\
\text { IGG }\end{array}$ & $\mathrm{El}$ \\
\hline $\begin{array}{l}14 \mathrm{~h} 00 \\
15 \mathrm{~h} 30\end{array}$ & $\begin{array}{l}\text { Pesquisa } \\
\text { Laboratório } \\
\text { TPG }\end{array}$ & $\begin{array}{l}\text { Planejamento } \\
\text { Laboratório } \\
\text { TPG }\end{array}$ & $\begin{array}{l}\text { Estatística } \\
\text { Laboratório } \\
\text { TPG }\end{array}$ & $\begin{array}{l}\text { Currículo } \\
\text { Laboratório } \\
\text { TPG }\end{array}$ & $\begin{array}{l}\text { Planejamento } \\
\text { Laboratório } \\
\text { TPG }\end{array}$ & $\mathrm{El}$ \\
\hline $\begin{array}{l}16 \mathrm{~h} 00 \\
18 \mathrm{~h} 00\end{array}$ & EI & $\mathrm{El}$ & $\begin{array}{l}\text { À disposição } \\
\text { da coordenação } \\
\text { Reunião dos } \\
\text { professores } \\
\text { El }\end{array}$ & $\mathrm{El}$ & $\mathrm{El}$ & \\
\hline
\end{tabular}

Como conseqüência dessa metodologia, os alunos deviam desenvolver uma série de trabalhos: ficha de leitura, informe escrito do trabalho em grupo, relatórios de visitas e eventos, além dos relatórios trimestrais que precisavam enviar para a coordenação do curso junto à OEA. Muitos dos trabalhos, principalmente os “informes”, eram publicados no órgão de divulgação do curso, intitulado Informa - Boletim do Centro de Ciências Pedagógicas da UFSM. Aos professores cabia a elaboração dos informes trimestrais, aos quais eram anexados todos os textos didáticos utilizados em sala de aula, tanto de autoria própria quanto de outras fontes. A maior parte da produção dos professores era composta por esse material, assim como as publicações no Informa. ${ }^{8}$

Como a ênfase do curso de mestrado era a relação teoria-prática, em conseqüência, na integração das disciplinas, o ensino se consolidava com a abordagem empírico-analítica de pesquisa, na qual o status de cientificidade se dava pela matematização dos da-

${ }^{8}$ Pode-se dizer que tudo era registrado, constituindo-se o conjunto dessa documentação um acervo inigualável para avaliar o cotidiano de uma instituição, suas realizações e as tendências que a influenciaram. dos, trabalhados estatisticamente. Nesse sentido, as pesquisas eram basicamente quantitativas.

Significativas alterações ocorreram no período compreendido entre 1970 e 1977, principalmente em 1976, na expectativa do fim do convênio. Embora renovado em 1973, tornava-se cada vez mais imperativo o credenciamento do curso de mestrado, para assegurar sua continuidade nos termos da legislação brasileira em vigor. Assim, em conformidade com o parecer CFE n ${ }^{\circ}$ 977/65, a estrutura curricular do curso de mestrado foi dividida em áreas de concentração e de domínio conexo. A matriz curricular passou a exigir, também, a realização de cursos de português (para os estrangeiros), espanhol ou inglês (para os brasileiros), e problemas brasileiros, desenvolvidos uma vez por semana, durante um semestre letivo.

As inovações propriamente metodológicas, denominadas pela coordenação de "novo enfoque metodológico” (Informa, 1976), foram idealizadas por Hernán Vera, chefe da seção de currículo do DAEOEA. A análise dos termos desse novo enfoque levanos a afirmar que se tratou de um aprimoramento do enfoque até então desenvolvido, uma vez que trocava o "laboratório" - espaço em que os problemas curriculares eram simulados - pela escolha de uma instituição escolar, na qual os problemas eram reais e as 
disciplinas tinham de ser trabalhadas em função dessa realidade. Aderia-se, assim, ao enfoque "aprender fazendo" em uma instituição escolar concreta.

Entre as atividades didático-pedagógicas desenvolvidas, devem ser destacadas as "missões", realizadas em instituições nacionais ou estrangeiras que manifestassem interesse em receber assessoramento no campo do planejamento e do desenvolvimento de currículo, e programas educacionais de ensino médio. Dessa maneira, eram previstas, no mínimo, duas assessorias por semestre, das quais participavam tanto professores quanto alunos. Esse tipo de atividade foi uma característica do curso de mestrado, geralmente não desenvolvida por outros cursos de pós-graduação. $\mathrm{O}$ atendimento à comunidade ou a instituições educacionais não era uma atividade meramente eventual ou de interesse do professor; ao contrário, eram planejadas sistematicamente e executadas na qualidade de assessoria propriamente dita. ${ }^{9}$ Dos resultados das investigações e aprendizagem in loco decorriam relatórios escritos, publicados internamente pela coordenação do curso de mestrado.

O material didático utilizado em sala de aula e a bibliografia indicada para os alunos demonstram forte influência das tendências desenvolvimentistas (Rostow), da teoria do capital humano (Schultz), do funcionalismo sistêmico (Parsons), do tecnicismo pedagógico reforçado pelo neobehaviorismo. Tais tendências tinham não só o aval das autoridades educacionais brasileiras, como seu estímulo, uma vez que os próprios documentos oficiais refletiam a penetração dessas concepções, ou seja, a profunda influência norte-americana no cenário nacional e no próprio convênio.

Outro elemento a ser considerado na análise do desenvolvimento do curso de mestrado é o processo

${ }^{9}$ Nos documentos oficiais da FIE encontramos o registro de assessorias nas seguintes localidades: Asunción (Paraguai); Boa Vista (à época Território Federal de Roraima); San José (Costa Rica); Bragança Paulista (São Paulo); Itu (São Paulo); Santana do Livramento, São Gabriel e São Borja (Rio Grande do Sul). de integração entre brasileiros e estrangeiros. Os trabalhos em equipe, cujo princípio de constituição era a heterogeneidade, contribuíam para a integração e a formação de amizades duradouras. Por sua vez, esse processo era facilitado pela participação dos alunos em eventos sociais e culturais na comunidade local e na região, ${ }^{10}$ assim como nas cerimônias oficiais da UFSM. Na abertura dos cursos e nas cerimônias de formatura sempre eram convidados, e compareciam, ministros de Estado, principalmente os da educação, além de representantes da OEA.

A projeção local, regional, nacional e internacional do curso de mestrado, dada sua natureza e constante cobertura da imprensa, deram a seus diretores, professores e alunos um status que lhes facilitava a realização de viagens, financiadas pela OEA ou pelo governo brasileiro, no país e no exterior, para a realização das “missões” e na participação de eventos.

\section{Encerramento do projeto multinacional}

A experiência da FIE pode ser dividida em dois períodos: o primeiro, correspondente à vigência do convênio entre o governo brasileiro e a OEA, de junho de 1969 a junho de 1973, marcado inicialmente pelos problemas de organização e planejamento, e posteriormente pelo aperfeiçoamento do sistema de planejamento e pela consolidação do curso; o segundo refere-se à renovação do convênio, de junho de 1973 a junho de 1977, marcado pelas preocupações com o credenciamento junto à CAPES e com a perspectiva de encerramento do convênio.

É necessário discutir e entender as razões do encerramento do convênio que possibilitou a experiência em pós-graduação em educação aqui relatada. Para isso, vamos analisar, de forma resumida, os dois lados envolvidos na sua formulação e execução: a OEA e a UFSM.

${ }^{10}$ Com a primeira turma, em 1970, foi elaborada uma programação na televisão local, durante dois meses, na qual os alunos estrangeiros eram entrevistados sobre a situação educacional de seus países. 
Nos documentos consultados, oriundos das reuniões anuais com a OEA, e na correspondência trocada no período de funcionamento do curso de pós-graduação, nada consta em desabono à administração da FIE. Periodicamente eram enviados especialistas para avaliar o projeto multinacional. Segundo o professor Milo Aita, coordenador do curso de 1970 a 1973, durante essas visitas realizavam-se levantamentos de dados e reuniões com o grupo gestor do Projeto, professores e alunos, cujos relatórios eram enviados para o DAE-OEA. ${ }^{11}$

Em edição do Jornal Especial, intitulada “A Interamericana”, é registrada em 4 de julho de 1971 a visita de um grupo avaliador da OEA, constituído pelos professores dr. Juan Rafael Llerena Amadeo (presidente), dr. Antonio Moreira Couceiro e dra. Lillian Aluralde. A reportagem relata a impressão que os avaliadores da OEA tiveram do curso:

Reunidos com professores do Curso de Pós-Graduação e mais tarde com alunos, ouviram de todos as opiniões sobre as atividades da Interamericana. A impressão causada pela Faculdade Interamericana foi muito boa, pelo nível cultural dos seus alunos e pelo gabarito do Corpo Docente especializado. (Jornal Especial, UFSM: nº 1, 1971, p. 10)

A OEA manteve permanente controle sobre todas as atividades do curso. As atividades didáticas eram acompanhadas também por meio dos "informes" (relatórios) que professores e alunos tinham que enviar trimestralmente à OEA, como podemos observar na transcrição do ofício-circular nº 5/72 (OEA, 1972b):

Por la presente me es grato acusar recibo de los informes que los alumnos becados de la OEA en el Curso Multinacional del Curriculum de Enseñanza Media me han hecho llegar.

De la lectura de ellos se desprende que las actividades programadas se han venido cumpliendo regularmente y que han logrado interesar vivamente a los alumnos.

${ }^{11} \mathrm{O}$ teor desses relatórios, conforme depoimento do professor Aita, não era do conhecimento da coordenação.
Me permito hacer llegar por su alto intermedio mis felicitaciones que hago extensivas a usted y al cuerpo de professores.

Dr. Alfonso Londoño - Diretor do Departamento de Assuntos Educativos da OEA

Os problemas internos do curso de mestrado eram de conhecimento da OEA, como se pode constatar na correspondência da direção para o dr. Hugo Albornoz, diretor do DAE-OEA. Embora não tenhamos encontrado o documento da OEA que desencadeou o assunto, é possível perceber que havia problemas, mas a direção local demonstrou domínio sobre a situação, como é possível ver na abertura da correspondência:

Em resposta a sua carta de 13 de março próximo passado, especialmente, tomando como ponto referencial aquele em que V. Excia. recomenda cautela quanto ao número de professores nacionais e/ou estrangeiros que foram submetidos à consideração e estudo desse prestigioso Departamento, cumpre-nos:

1. Esclarecer, que, em momento nenhum, o ingresso de um professor nacional e/ou estrangeiro, no desenvolvimento dos nossos cursos, permitiu o risco da perda dos objetivos dos mesmos ou a desintegração do processo ensino-aprendizagem, visto que eles se desenvolvem sobre planejamentos que independente do professor que os ministre, não permitem a quebra de continuidade. (UFSM, 1975a).

Questões como essa não alteraram, ao que parece, as relações de confiança e seriedade estabelecidas, conforme podemos ver na correspondência de 25 de setembro de 1975 do professor visitante Ovidio Soto Blanco, da qual citaremos apenas a passagem que nos interessa:

Siento una honda de satisfaccion por el trabajo realizado. El grupo de profesores/alumnos, en terminos generales, está compuesto por profesionales que esperan los mejores resultados de su capacitación. Hay inquietudes constantes y se observa un interés muy marcado a fin de aprovechar el tiempo que les resta para encontrar el panorama integrador 
en su formación que han venido a buscar a esta Universidad.

La respuesta la estan dando ustedes com toda responsabilidad.

A professora Ladyr Anchietta da Silveira assumiu a direção do projeto multinacional, na fase de conclusão da sétima e última turma do convênio. Em outubro de 1977, essa coordenadora encaminhou à administração superior o novo regulamento do curso, já desvinculado do convênio, abrangendo duas áreas de concentração: teoria e prática de currículo, e métodos e técnicas de ensino.

Do lado da UFSM, o encerramento do convênio era mais complexo, porque a continuidade do mestrado poderia vir a ser comprometida, uma vez que o mesmo não era credenciado. ${ }^{12}$ Essa questão era preocupante, e a necessidade do credenciamento era clara entre os professores e coordenadores.

Em 1974, a diretora encaminhou ofício ao reitor, na época o professor dr. Hélios Homeros Bernardi, na qual anexa o parecer CFE n ${ }^{\circ}$ 93/70, referente a cursos credenciados e centros regionais de pós-graduação, que se relaciona com o pedido de credenciamento do curso, feito pela administração superior da UFSM, e cópia do protocolo do CFE no qual é registrado o arquivamento do processo. Nessa correspondência a diretora esclarece que essa não é a primeira vez que tenta resolver o problema de credenciamento:

Desejamos, outrossim, esclarecer que em 09/12/69 enviamos o processo ao então Magnífico Reitor Prof. Dr. Mariano da Rocha Filho, solicitando-lhe o obséquio de encaminhá-lo ao CFE. (UFSM, 1974)

${ }^{12}$ Entendemos que o reitor José Mariano da Rocha Filho, naquela ocasião membro do CFE, tendo conhecimento da concepção dos centros regionais de pós-graduação e das possíveis implicações que poderiam advir para Santa Maria, já que a sede do centro regional no Sul era em Porto Alegre, na Universidade Federal do Rio Grande do Sul (UFRGS), preferiu trocar a regra pela exceção e, ao fazê-lo, com o intuito de proteger o curso, manteve-o à margem do sistema, optando pelo não-credenciamento.
O reitor escreve, no próprio ofício, a seguinte observação:

Em contato pessoal com o Senador Tarso Dutra, dele colhi parecer pelo qual entende desnecessário o credenciamento do Curso pelo CFE, porque resulta de acordo multinacional, entre o Governo Brasileiro [...] e uma entidade internacional, a OEA. (idem)

Como se pode deduzir, a interpretação era consensual entre os responsáveis maiores, tanto que constava do parecer $n^{\circ} 93 / 70$ a seguinte ressalva: "De acordo. Ressalvado os direitos legais inerentes aos centros de pós-graduação resultantes de acordos multinacionais firmados pelo Brasil” (Brasil, 1970, p. 231). ${ }^{13}$

Dessa forma, a situação inicial ficava mantida e a idéia de credenciamento arquivada, pelo menos enquanto durasse o convênio. A preocupação do grupo envolvido com a FIE era sua situação legal, quando o convênio não fosse mais renovado, pois não fazia parte da política da OEA a permanência muito prolongada de um projeto desse tipo em uma mesma localidade. Dessa forma, a questão do credenciamento do curso continuou. Em agosto de 1975, pelo ofício $n^{\circ}$ 0717/ 75, o pró-reitor de pós-graduação informa ao reitor:

1. Face às informações obtidas junto ao Egrégio CFE, a respeito da situação e necessidade de ser organizado o devido expediente visando o credenciamento do Curso de Pós-Graduação em Educação, em data de 24/março/1975, a Sra. Decano do Centro de Ciências Pedagógicas designou um Grupo de Trabalho para ser iniciado o estudo pertinente.

2. O Grupo de Trabalho, integrado pelas docentes Therezinha Veras, Dilma da Luz Pereira e Ladyr Anchietta da Silveira, foi efetivamente constituí-

${ }^{13} \mathrm{O}$ título do documento era "Cursos Credenciados e Centros Regionais de Pós-Graduação”. Tratava-se de uma consulta da conselheira Nair Fortes sobre a criação de centros regionais de pós-graduação. 
do pela Portaria n.003/75, assinada pela Prof. Adj. Carmem Silveira Netto.

3. Visando apressar o trabalho de montagem do processo, eis que dirigi ofício à Sra. Decano (cópia anexo).

Atendo-me, ao parecer emanado da Assessoria Técnica da CAPES, cuja cópia foi enviada com o ofício referido, no início do presente, permito-me, Senhor Professor Reitor, registrar que a remessa do Plano de Operações Curso de Pós-Graduação em Educação - 1974/75 não resultou de minha iniciativa e/ou proposição. (UFSM, 1975b)

Com referência a essa última e polêmica questão, o diretor da CAPES, Darci Closs, encaminhou parecer sobre o Plano de Operações 1974/1975:

O Plano de Operações submetido pelo Curso de PósGraduação em Educação da UFSM não fornece maiores detalhes, entre outros, quanto ao corpo docente com titulação de doutorado, engajado em regime de dedicação exclusiva na orientação das dissertações de mestrado. A possibilidade de defender tese num prazo de até 2 (dois) anos sem permanência no local para desenvolver a pesquisa parece-nos desaconselhável, especialmente se levarmos em conta a falta de tradição de pesquisa. Finalmente, o prazo de 10 (dez) meses para a obtenção da totalidade dos créditos é pequeno, se comparado com a média dos demais cursos de mestrado em Educação. Em vista da exigüidade de dados, do compromisso internacional com a OEA, do pequeno montante de recursos, descontados os US\$ 60.000,00 para bolsas, somos de parecer que o projeto deveria ser apoiado, com a ressalva de que o curso fosse obrigado a solicitar o devido credenciamento junto ao CFE, para assegurar aos brasileiros inscritos no programa a validade do diploma.

Os termos do parecer da CAPES eram claros: apoio, com a condição de que o curso efetivasse seu credenciamento. A partir desse parecer a questão agravou-se, provocando uma crise no mestrado e uma certa perda de sua credibilidade junto à comunidade acadêmica.

Ante esses acontecimentos, podemos concluir que esforços não faltaram, por parte da direção do curso, para adequá-lo às exigências da legislação brasileira, seja definindo as áreas de concentração e domínio conexo, e em conseqüência a reformulação da matriz curricular, seja ao melhorar o nível de qualificação do corpo docente, conforme constatado nos planos de curso de 1976 e 1977.

Após o encerramento do convênio, no primeiro semestre de 1977, permanecendo a sétima e última turma até dezembro, ainda com amparo legal do mesmo, foi encaminhado ao Conselho de Ensino, Pesquisa e Extensão (CEPE) da UFSM, em 22/8/1977, o processo ${ }^{\circ}$ 588/77, intitulado Projeto de Reestruturação do Curso de Pós-Graduação em Educação, aprovado pelo parecer CEPE $n^{\circ}$ 178/77. O mestrado passou a ter então as duas áreas de concentração propostas: teoria e prática do currículo, e métodos e técnicas de ensino. Posteriormente passou por novas alterações, recebendo essas áreas a denominação de currículo e metodologia do ensino. No entanto, o encerramento do convênio e a aprovação da reestruturação não suprimiram os estragos feitos pela falta de credenciamento, estragos estes que não estiveram ligados ao sucesso ou insucesso da proposta do curso de mestrado oferecido pela FIE.

\section{Considerações finais}

Que lições poderíamos tirar da experiência do projeto multinacional que deu origem ao curso de mestrado em educação desenvolvido pela Faculdade Interamericana de Educação da Universidade Federal de Santa Maria? Essa experiência contribuiu de alguma forma para a constituição da pós-graduação stricto sensu brasileira? Essas questões tornar-se-iam complexas, se respondidas fora do contexto histórico em que o projeto multinacional foi criado e desenvolvido. No entanto, é possível fazer algumas inferências considerando o atual estágio da pós-graduação brasileira.

Com base na investigação realizada, é possível destacar alguns aspectos dessa experiência. Iniciamos pelos pontos negativos da proposta, visando compreender como cercearam as potencialidades dos pontos positivos que ela apresentou. 
O ponto mais frágil foi a total dependência do projeto multinacional à política de pós-graduação da OEA, inspirada, de maneira geral, na concepção de mundo liberal-capitalista do bloco ocidental. A dependência a essa concepção ideológica definiu as diretrizes pedagógicas do curso, que resultaram em pressupostos epistemológicos dentro do modelo empírico-analítico de pesquisa e de concepções pedagógico-didáticas tecnicistas, de inspiração neobehaviorista.

Outro ponto negativo foi a incompatibilidade entre a proposta do projeto multinacional e a legislação de pós-graduação brasileira, vigente desde 1965. O referido projeto não contemplava alguns dos critérios emanados dessa legislação: corpo docente permanente com titulação de doutor na área de conhecimento do curso de mestrado e produção científica relevante; natureza híbrida do curso, que permitia a opção pelo grau de especialista ou mestre, o que descaracteriza a proposta de pós-graduação stricto sensu; realização dos créditos e da dissertação de mestrado em apenas dois semestres letivos.

Em contrapartida, é possível indicar os avanços propostos pelo projeto multinacional que, indiretamente, contribuíram para a expansão e a concepção atual da pós-graduação stricto sensu. Em primeiro lugar, a experiência motivou a interiorização da pós-graduação. Em segundo, a obrigatoriedade da dedicação de tempo integral ao curso de mestrado por parte dos alunos, assim como o planejamento integrado de todas as atividades do referido curso e a participação do corpo docente na execução interdisciplinar das atividades didático-científicas. Por último, a busca da relação teoria-prática-teoria, o ponto forte do curso, envolvendo os alunos na identificação e solução dos problemas educacionais.

Portanto, em que pese a não-adequação do curso de mestrado à legislação da época, e a concepção ideológica implícita nas políticas educacionais que lhe serviram de suporte epistemológico, podemos inferir que a experiência da Faculdade Interamericana de Educação foi importante na constituição da pós-graduação stricto sensu no Brasil.
CLOVIS RENAN JACQUES GUTERRES, mestre em educação pelo Convênio Universidade Federal de Santa Maria (UFSM)/ Organização dos Estados Americanos (UFSM/OEA) e doutor em educação pelo Convênio Universidade Estadual de Campinas (UNICAMP), é professor no Centro de Educação da UFSM. Últimas publicações: Filosofia e educação básica (In: TREVISAN, A. L., ROSSATO, N. D. (orgs.). Filosofia e educação: confluências (Santa Maria: FACOS/UFSM, 2005); Conhecimento, política e educação em John Locke (Revista Vydia, Santa Maria, v. 15, nº 26, jul.-dez. 1996, p. 85-103); Reflexões sobre a Escola de Frankfurth (Revista Vydia, Santa Maria, v. 17, nº 30, jul.-dez. 1998, p. 57-67). Pesquisa atual: Construções teórico-metodológicas da educação.E-mail: crguterres@hotmail.com

OSWALDO ALONSO RAYS, mestre em filosofia pela UFSM e doutor em educação pelo Convênio UFSM/UNICAMP, é professor titular aposentado da UFSM e, atualmente, professor no Centro Universitário Franciscano de Santa Maria. Últimas publicações: O poema pedagógico makarenkiano: princípios político-pedagógicos (Santa Maria: Pallotti, 2003); Formação de professores: uma alternativa de dinâmica curricular (Revista Educação, Santa Maria, v. 29, nº 2, 2004, p. 150-174); A aula: perspectiva crítico-dialética (Revista Educação e Cidadania, Campinas, v. 3, nº 1-2, 2004, p. 93-106). Pesquisa atual: Construções teórico-metodológicas da educação.E-mail: alonsorays@hotmail.com

\section{Referências bibliográficas}

A CRÔNICA DA OEA (Publicação bimestral da União Pan-Americana), (1968). Rio de Janeiro, Serviço Gráfico do Instituto de Geografia e Estatística, v. 3, n 5, abr.

BICUDO, Hélio, (2002). Conferência Nacional de Direitos Humanos. Disponível em: <http://www.dhnet.org.br/direitos/militantes/heliobicudo/bicudo_magna.htm>. Acesso em: abr. de 2005. BRASIL, (1970). Parecer no 93/70. Documenta, Rio de Janeiro: $\mathrm{n}^{\circ}$ 111, fev., p. 229-231

(1965). Parecer no 977/65. Documenta, Brasília: MEC/ CFE, no 44, dez., p. 67-88.

GUTERRES, Clovis R. J., (2001). A Faculdade Interamericana de Educação. Projeto Multinacional de Aperfeiçoamento de Pessoal Especializado em Educação, 1970-1977. Tese de doutorado. Universidade Federal de Santa Maria (Convênio UFSM/ UNICAMP - Faculdade de Educação). 
INFORMA - Boletim do Centro de Ciências Pedagógicas da UFSM,

(1970). A segunda reunião preparatória da Faculdade Interamericana. Santa Maria, ano I, nº 1, jun., p. 9-13.

, (1976). Novo enfoque metodológico. Santa Maria, ano

VI, $n^{\circ} 1$, mar., p. 7-12.

OEA - Organização dos Estados Americanos, (1968). Proyecto Multinacional de Perfeccionamiento de Personal Especializado en Educación: Programa de Desarrollo Educativo. Resolução $n^{\circ}$ 10/68 da Comissão Executiva do Consejo Interamericano Cultural (CECIC). Washington: Departamento de Assuntos Educativos.

(1969a). Informe final de la Primeira Reunion. Washington, Secretaria General de la Organización de los Estados Americanos, 7 a 22 de noviembre.

, (1969b). Segunda Reunión. Critérios y Procedimientos para la Operación de los Programas Regionales de Desarrollo Educativo y de Desarrollo Cientifico y Tecnologico. Washington, 22 a 29 de abril.

, (1972a). Manual. Washington (DC): Secretaria General de la OEA / Departamento de Información y Asuntos Públicos / Secretaria General de la OEA.

, (1972b). Ofício-circular n ${ }^{\circ}$ 5/72. Washington, (DC): OEA/ Departamento de Assuntos Educativos da OEA.

REITOR propõe Universidade das Américas, (1968). Correio da Manhã, Rio de Janeiro, 16 fev.
UFSM - Universidade Federal de Santa Maria, (1968). Projeto de ensino superior: Faculdade Interamericana de Educação. Santa Maria: UFSM. , (1970). Programa geral: curso de pós-graduação sobre teoria e prática de currículo para nível de ensino médio. Santa Maria: MEC/UFSM/Departamento de Educação da OEA. , (1974). Ofício $n^{\circ}$ 421/74. Santa Maria: UFSM/Curso de pós-graduação em educação. , (1975a). Ofício $n^{\circ}$ 93/75. Santa Maria: UFSM/Curso de pós-graduação em educação. , (1975b). Ofício $n^{\circ}$ 0717/75. Santa Maria: UFSM/ Pró-Reitoria de Pós-Graduação e Pesquisa. , (1976). Plano Operacional, 1976 e 1977. Planos de Curso: Faculdade Interamericana de Educação. Santa Maria: UFSM.

, (1977). Parecer $n^{\circ}$ 178/77. Conselho de Ensino Pesquisa e Extensão. Santa Maria: UFSM.

ROCHA FILHO, J. Mariano da, (1962a). A nova universidade. Porto Alegre: Globo \& Associação Pró-Ensino Superior. , (1962b). A universidade e o progresso da humanidade. In: . A nova universidade. Porto Alegre: Globo \& Associação Pró-Ensino Superior, p. 11-17.

Recebido em abril de 2005 Aprovado em junho de 2005 


\section{Resumos/Abstracts}

Clovis Renan Jacques Guterres e

Oswaldo Alonso Rays

A Faculdade Interamericana de

Educação na expansão da pós-

graduação no Brasil

Neste texto procuramos destacar e comentar aspectos substantivos da primeira fase do atual Programa de Pós-

Graduação em Educação da

Universidade Federal de Santa Maria, RS, oriundo de um projeto

multinacional desenvolvido na forma de convênio entre o Governo Brasileiro e a Organização dos Estados Americanos (OEA), no período de 1970 a 1977.

Esse Projeto que passa a ser denominado como Faculdade Interamericana de Educação (FIE) foi o responsável pela implantação e desenvolvimento de um dos primeiros programas de mestrado em educação no interior do Brasil. Para o entendimento sucinto de suas implicações para o processo de expansão da pós-graduação no Brasil, procuramos reconstruir sua trajetória a partir do contexto da Guerra Fria, das determinações da política de integração da OEA e da política de expansão da pós-graduação stricto sensu no Brasil.

Palavras-chave: Faculdade Interamericana de Educação; política de integração da OEA; política de pós-graduação no Brasil

The Interamerican College of Education in the expansion of the post-graduation in Brazil

In this text we aimed at highlighting and commenting substanctive aspects of the first phase of the current PostGraduation Program in Education from the Universidade Federal de Santa Maria, $R S$, originally from a multinational project developed in the form of a covenant between the Brazilian Government and the Organization of American States (OAS), in the period from 1970 to 1977. This project which is denominated as Faculdade Interamericana de Educação (Interamerican College of EducationFIE) was the responsible by the implantation and development of one of the first Education Master's Program in the contryside of Brazil. For the brief understanding of its implications for the Post-Graduation espansion process in Brazil, we aimed at rebuilding its trajectory from the Cold War context, from the determinations of the OAS integration policy and the stricto sensu post-graduation expansion policy in Brazil.

Key-words: Interamerican College of Education; OAS integration policy; post-graduation policy in Brazil 